\title{
Parental age and motor neuron disease
}

\author{
C H HAWKES, * P O GOLDBLATT, $\dagger$ M SHEWRY $\ddagger$ A J FOX $\dagger$ \\ From the Department of Neurology, Ipswich Hospital, ${ }^{*}$ Ipswich, Social Statistics Research Unit, $\dagger$ and \\ University Statistical Laboratory, $\ddagger$ City University, London, UK
}

SUMMARY A case-control approach was used to study the relationship between parental age and motor neuron disease (MND) in a nationally representative sample of men. [The method, involving a search for parents' records in the NHS Central Register, is new and may be of interest in other conditions where parental age is thought to play a part.] The parents of men who died of MND in 1979 were not older than the parents of sex, age and regionally standardised controls who died in the same year.

Motor neuron disease (MND) is a rapidly fatal progressive muscle wasting disease of unknown cause. In approximately $5 \%-10 \%$ of clinically typical MND patients a pattern of autosomal dominant inheritance is observed ${ }^{1}$ whilst in the commoner sporadic form autosomal recessive inheritance has been proposed ${ }^{2}$ but awaits proof. The effect of birth order (but not maternal age) has been examined in a small series ${ }^{3}$ with negative results.

According to Appel ${ }^{4}$ MND, Alzheimer's disease (AD) and Parkinson's disease are fundamentally similar and all may be due to lack of a specific neurotrophic hormone. Gajdusek has proposed ${ }^{5}$ that many chronic degenerative diseases of the CNS (including the latter three) may be due to interference with axonal transport of neurofilaments. Others ${ }^{6}$ postulate that in such disorder there is subclinical damage to specific regions of the CNS which remains dormant for several decades only to become clinically manifest when age-related neuronal loss takes place. Occasionally amyotrophy and fasciculation is seen in AD; conversely some patients with MND exhibit dementia. ${ }^{7}$ Histologically few similarities exist between sporadic MND and AD but there are features common to the Guam type and $A D$, viz neurofibrillary tangles, and on occasion pathological changes of Guam type MND are found in the sporadic MND. ${ }^{8}$

It has been claimed ${ }^{9}{ }^{10}$ that patients with early onset AD display increased prevalence of Down's syndrome in relatives, but this could not be confirmed by others. ${ }^{112}$ The majority of patients with Down's syndrome over 40 years develop an Alzheimer-type

Address for reprint requests: Dr C $\mathbf{H}$ Hawkes, Department of Neurology, Ipswich Hospital, Ipswich IP4 SPD, UK.

Received 1 November 1988 and in revised form 9 January 1989. Accepted 16 January 1989 dementia $^{1314}$ and it is well established ${ }^{15}$ that many individuals with Down's syndrome are born to elderly mothers. Hence it was recently proposed ${ }^{11}$ that advanced maternal age may be an important factor in the development of $\mathrm{AD}$ in their children. This led to a number of investigations which looked for a connection between $A D$ and parental age. Results were conflicting ${ }^{1121617}$ and probably were so because of differences in methodology.

Using a novel approach designed to avoid sampling bias we examined the influence of parental age and $\bar{\theta}$ subsequent development of MND. The relationships between both timing and causes of early mortality among parents and siblings of MND cases was also appraised.

\section{Methods}

To determine if MND is associated with parental age it is necessary to identify a representative sample of MND cases and a parallel sample of controls, then compare the ages of parents for each group. Simple power calculations suggest that a series of 100 cases and 100 controls would have a $50 \%$ chances of detecting a two year difference in parental age at the $1 \%$ level of significance.

A national sample of MND cases and controls was obtained from the Office of Population Censuses and Surveys (OPCS) who listed all MND deaths in 1979 to people born in 1923-1936. For each possible case from the list of MND deaths in 1979 OPCS identified a control person who had also died in the same year. Controls were selected from a computer tape of all deaths in 1979 , choosing at random nonMND deaths who were of similar sex, born within 2 years of the case and living in the same part of the country.

The years of birth (1923-1936) were chosen to take advantage of the original construction of the National Health Service Central Register (NHS-CR-established in 1939). Since it was derived from the 1939 National Register many of the original records were in family and household order. We wished to select a sample of cases and controls with 
Table 1 Results of tracing at NHS Central Registry

\begin{tabular}{lcc}
\hline Outcome of search & Cases & Controls \\
\hline Total sent & 96 & 96 \\
First search & & \\
Person traced in 1939 household & 72 & 62 \\
Not traced: Non 1939 NHS number & 20 & 27 \\
$\quad$ Not traced: no NHS number & 4 & 7 \\
Second search & 20 & 16 \\
Both parents found & 3 & 3 \\
One parent found & 1 & 2 \\
No parents found & - & 10 \\
Person born outside England and Wales & - & 3 \\
Person not traced & - & \\
\hline
\end{tabular}

a high probability of being included in the original records at the same dwellings as their parents.

For each case-control pair copies of the original death certificates were used to search (in NHS-CR) for the appropriate household in order to identify mothers, fathers and any other relatives who lived at the same address in 1939. This method of tracing parents was supplemented by a search of birth and marriage indexes where necessary. For each relative found in the NHS-CR a note was made of the dates of birth and death, causes of death, social class and whether lost to follow up.

\section{Results}

The results of the tracing exercise are summarised in table 1. Death records for 1979 yielded 96 cases and controls which were originally sent to NHS-CR. Of these, 72 cases and 62 controls were located at first search. A second search which made use of informa-

Table 2 Numbers of parents found in 82 matched and traced pairs

\begin{tabular}{|c|c|c|}
\hline & Cases & Controls \\
\hline Number of case-control pairs & \multicolumn{2}{|c|}{$82(45)$} \\
\hline $\begin{array}{l}\text { Unmatched comparisons } \\
\text { number of fathers traced } \\
\text { number of mothers traced }\end{array}$ & $\begin{array}{l}57(35) \\
56(35)\end{array}$ & $\begin{array}{l}55(33) \\
55(35)\end{array}$ \\
\hline $\begin{array}{l}\text { Matched comparisons } \\
\text { Both fathers traced } \\
\text { Both mothers traced }\end{array}$ & \multicolumn{2}{|c|}{$\begin{array}{l}32(27) \\
33(29)\end{array}$} \\
\hline
\end{tabular}

Figures in brackets are based on first search (using death certificates only).
Table 3 Comparison of ages of cases and controls

\begin{tabular}{llll}
\hline & & \multicolumn{2}{l}{82 matched pairs } \\
\cline { 3 - 4 } Difference in ages & All & $\begin{array}{l}\text { Both } \\
\text { fathers } \\
\text { traced }\end{array}$ & $\begin{array}{l}\text { Both } \\
\text { mothers } \\
\text { traced }\end{array}$ \\
\hline Numbers in which: & & & \\
(a) case older & $24(32 \cdot 8)$ & $7(12 \cdot 8)$ & $9(13 \cdot 2)$ \\
(b) same age & $19(16 \cdot 4)$ & $7(6 \cdot 4)$ & $8(6 \cdot 6)$ \\
(c) control older & $39(32 \cdot 8)$ & $18(12 \cdot 8)$ & $16(13 \cdot 2)$ \\
Total & 82 & 32 & 33 \\
Chi-squared (2 df) & 3.9 & $4 \cdot 8$ & $2 \cdot 2$ \\
& $(\mathrm{p}>0.05)$ & $(\mathrm{p}>0.05)$ & $(\mathrm{p}>0.05)$ \\
\hline
\end{tabular}

Figures in brackets are the expected distribution based on the assumption of no differences in age between cases and controls.

tion found on marriage and birth records identified the 1939 households for every case and all except 13 controls. Ten of these controls were born outside England and Wales and were omitted from analysis. Table 2 gives details of the 82 case-control pairs where at least one of the parents of both case and control was traced, the number of times fathers and mothers were traced and the occasions when this was true for both cases and controls. These data may be analysed making no use of the matching in which case the age differences would be based on 55 mothers or fathers, or if matching was used it would be based on 32 matched fathers and 33 matched mothers.

Table 3 indicates that there was a tendency for the controls to be older than the cases. This is not surprising given that even within a small age group older people are more likely to die. However none of the differences was statistically significant. Nevertheless these differences were controlled for later in age comparisons of mothers and fathers.

Table 4 compares the mean ages of mothers and fathers of cases and controls without taking account of matching. Controls were found to have older fathers and mothers. For fathers the difference in mean ages was 1.6 years; for mothers it was only 0.3 years. However, neither of the differences was significant $(\mathrm{p}>0.05)$.

Table 5 compares ages of mothers and fathers in case control pairs. Again most comparisons suggest that controls have older parents than cases, the only exception being the comparison of mothers where the case was younger than the control. In none of the

Table 4 Differences in mean ages of mothers and fathers (unmatched comparison)

\begin{tabular}{|c|c|c|c|c|c|c|c|c|}
\hline \multirow[b]{2}{*}{ Age } & \multicolumn{3}{|l|}{ Case } & \multicolumn{3}{|c|}{ Control } & \multirow[b]{2}{*}{$t$ test ${ }^{*}$} & \multirow[b]{2}{*}{$95 \%$ limits $\dagger$} \\
\hline & Mean & $S D$ & $n$ & Mean & $S D$ & $n$ & & \\
\hline $\begin{array}{l}\text { Father } \\
\text { Mother }\end{array}$ & $\begin{array}{l}32 \cdot 14 \\
30 \cdot 32\end{array}$ & $\begin{array}{l}5.8 \\
5.6\end{array}$ & $\begin{array}{l}57 \\
56\end{array}$ & $\begin{array}{l}34 \cdot 21 \\
30 \cdot 62\end{array}$ & $\begin{array}{l}7 \cdot 5 \\
6 \cdot 51\end{array}$ & $\begin{array}{l}53 \\
55\end{array}$ & $\begin{array}{l}-1.6 \\
-0.3\end{array}$ & $\begin{array}{l}-4 \cdot 7,0 \cdot 5 \\
-2 \cdot 6,2 \cdot 0\end{array}$ \\
\hline
\end{tabular}

*t statistic for difference in means.

†Approximate $95 \%$ confidence interval for difference in mean ages (case-control). 
Table 5 Paired differences in ages of parents at birth (case versus control)

\begin{tabular}{|c|c|c|c|c|c|c|c|c|}
\hline \multirow{2}{*}{$\begin{array}{l}\text { Difference between } \\
\text { case \& control }\end{array}$} & \multicolumn{4}{|l|}{ Father } & \multicolumn{4}{|l|}{ Mother } \\
\hline & Mean & $S D$ & $N$ & $95 \%$ & Mean & $S D$ & $N$ & $95 \%$ \\
\hline
\end{tabular}

matchings was the observed difference large enough to reach statistical significance.

\section{Discussion}

By taking MND cases from all deaths in one year a nationally representative sample of patients was generated which allowed matching on the basis of sex, age and region of residence with all other people dying in the same year. This approach overcomes the problem of bias common to many case-control studies based on sampling obtained from for example, members of disease orientated Associations or patients attending hospital. Table 1 suggests that it would also have been advantageous to have matched on country of birth, say by restricting the study to people born in England and Wales.

Despite these obvious advantages there remain three important drawbacks to the approach. First, fewer parents than anticipated were traced. Second the work involved at OPCS was detailed, costly and time consuming and we had little control over timetables. Third, the amount of information available in the OPCS record system is confined to factual information about certain key events and is limited to the type of information collected by the vital registration system. As a result the hypotheses that could be addressed using this approach were retricted.

It should be clear from tables 4 and 5 that our failure to find an association between maternal age and MND is not a result of small sample size. Almost all the comparisons made suggest if anything that parents of men who died of motor neuron disease were younger than parents of other men who died at the same time. Because men tend to marry women slightly younger than themselves one might discount the similarity between findings for fathers and mothers.

Whilst the approach used in our study is free of sampling error it does rely heavily on the diagnostic accuracy of death certificates. This problem was addressed $^{18}$ in a North Carolina study. In a group of 72 patients in whom the diagnosis of MND was made by several neurological centres, the death certificates listed MND correctly in 52 $(72 \%)$. Ten patients known to have MND had multiple sclerosis itemised as the cause of death. When MND is given as a cause of death it was noted as the primary cause in $80-90 \%$ of certificates according to data from Norway and the Netherlands. ${ }^{19}$ These relatively minor sources of error would not detract from our overall conclusion.

As well as identifying the date of birth of the case and control parents, the approach to the NHS-CR enabled us to look at the timing and pattern of mortality among those parents who had died. This did not suggest any intergenerational links with causes of death which might be associated with MND but the number of deaths examined (14) was small.

This study was supported by a grant from Action Research for the Crippled Child. It would not have been possible, nor have achieved such a high trace rate, had it not been for the persistence of OPCS staff both in the Medical Statistics Division in London and in the NHS Central Registry at Southport.

\section{References}

1 Emery AGH, Holloway S. Familial Motor Neurone Diseases. In: Rowland LP, ed. Human Motor Neurone Diseases. New York: Raven Press, 1982:139-47.

2 Alter M, Schauman. Hereditary amyotrophic lateral sclerosis. Eur Neurol 1976;14:250-65.

3 Levey KM. In: Discussion on motor neurone disease. Proc R Soc Med 1962;55:1031-2.

4 Appel SH. A unifying hypothesis for the cause of amyotrophic lateral sclerosis. Ann Neurol 1981;10: 499-505.

5 Gajdusek DC. Hypothesis: interference with axonal transport of neurofilament as a common pathogenic mechanism in certain diseases of the central nervous system. N Engl J Med 1985;312:714-9.

6 Calne DB, Eisen A, McGeer E, Spencer PS. Alzheimers disease, Parkinsons Disease and Motor Neurone Disease; abiotropic interaction between ageing and environment? Lancet 1986;ii:1067-70.

7 Hughes JT. Motor neurone disease and dementia. In: Rose, F Clifford, ed. Research Progress in Motor Neurone Disease. London: Pitman Books, 1984: 304-311.

8 Meyers KR, Dorencamp DG, Suzuki K. Amyotrophic lateral sclerosis with diffuse neurofibrillary changes. Arch Neurol 1974;30:84-89.

9 Heston LL, Mastri AR, Anderson VE, White J. Dementia of the Alzheimer type. Clinical genetics, natural history and associated conditions. Arch Gen Psychiatry 1981;38:1085-90.

10 Heyman A, Wilkinson WE, Stafford JA, et al. Alzheimers 
disease: a study of epidemiological aspects. Ann Neurol 1984;15:335-41.

11 Cohen D, Eisdorfer C, Leverenz J. Alzheimers disease and maternal age. J Am Geriatr Soc 1982;30:656-9.

12 Whalley LJ, Carothers AD, Collyer S, de Mey R, Frackiewicz A. A study of familial factors in Alzheimers disease. Br J Psychiatry 1982;140:249-56.

13 Ball, MD, Nuttal K. Neurofibrillary tangles, granulovacuolar degeneration and neuronal loss in Downsyndrome:quantitative comparison with Alzheimer dementia. Ann Neurol 1980;7:462-5.

14 Ellis WG, McCullough JR, Corley CL. Presenile dementia in Down's syndrome: ultrastructural identity with Alzheimer's disease. Neurology 1974;24:101-6.

15 Lilienfeld AM. Epidemiology of Mongolism. Baltimore:
Johns Hopkins Press, 1969:145.

16 Amaducci LA, Fratiglioni L, Rocca WA, et al. Risk factors for clinically diagnosed Alzheimer's disease: a case-control study of an Italian population. Neurology 1986;36:922-31.

17 English D, Cohen D. A case control study of maternal age in Alzheimers disease. J Am Geriatr Soc 1985;33:167-9.

18 Hoffman PM, Brody JA. The reliability of death certificate reporting for amyotrophic lateral sclerosis. $J$ Chron Dis 1971;24:5-8.

19 Kurland LT, Choi NW, Sayre GP. Implications of incidence and geographic patterns on the classifications of amyotrophic lateral sclerosis. In: Norris FH, Kurland LT, eds. Motor Neurone Diseases. New York: Greene and Straton, 1969:28-50. 